\title{
Intramolecular carbonickelation of alkenes
}

\author{
Rudy Lhermet, Muriel Durandetti ${ }^{*}$ and Jacques Maddaluno*
}

Open Access

\author{
Full Research Paper \\ Address: \\ Laboratoire COBRA, CNRS UMR 6014 \& FR 3038, Université de \\ Rouen, INSA de Rouen, 1 rue Tesnières, 76821 Mont St Aignan \\ Cedex, France \\ Email: \\ Muriel Durandetti* - muriel.durandetti@univ-rouen.fr; \\ Jacques Maddaluno* - jmaddalu@crihan.fr \\ * Corresponding author \\ Keywords: \\ alkenes; carbometallation; carbonickelation; cyclization; Heck-type \\ reaction; nickel catalysis
}

Beilstein J. Org. Chem. 2013, 9, 710-716.

doi:10.3762/bjoc.9.81

Received: 14 January 2013

Accepted: 14 March 2013

Published: 12 April 2013

This article is part of the Thematic Series "Carbometallation chemistry".

Guest Editor: I. Marek

(C) 2013 Lhermet et al; licensee Beilstein-Institut.

License and terms: see end of document.

\begin{abstract}
The efficiency of the intramolecular carbonickelation of substituted allylic ethers and amines has been studied to evaluate the influence of the groups borne by the double bond on this cyclization. The results show that when this reaction takes place, it affords only the 5-exo-trig cyclization products, viz. dihydrobenzofurans or indoles. Depending on the tethered heteroatom (O or N), the outcome of the cyclization differs. While allylic ethers are relatively poor substrates that undergo a side elimination and need an intracyclic double bond to proceed, allylic amines react well and afford indoline and indole derivatives. Finally, the synthesis of the trinuclear ACE core of a morphine-like skeleton was achieved by using $\mathrm{NiBr}_{2}$ bipy catalysis.
\end{abstract}

\section{Introduction}

Carbometalation is a reaction involving the addition of an organometallic species to a nonactivated alkene or alkyne to form a new carbon-carbon bond and generate a new organometallic entity, which may subsequently undergo synthetic transformations [1,2]. Even though these reactions have been known for over 85 years [3], they have emerged as practical organometallic tools only during the past forty years, in particular through the development of palladium chemistry [4]. The catalytic cycle starts with the oxidative addition of $\operatorname{Pd}(0)$ to generate a $\sigma$-arylpalladium(II), then a rapid insertion of a double or triple bond takes place [5]. This method was particularly applied in the "Mizoroki-Heck reaction" [6] for the syn- thesis of pharmaceutical and agrochemical intermediates using nonactivated olefins with high regio- and stereoselectivity [7]. Besides the typical intermolecular version, some intramolecular variants were developed leading to useful heterocycles [8-10]. Even if palladium is very efficient, nickel appears to be among the most promising metallic substitutes [11]. However, the tedious preparation of $\mathrm{Ni}(0)$ complexes such as $\mathrm{Ni}(\operatorname{cod})_{2}$ explains that nickel chemistry is hardly perceived as a realistic alternative to palladium, except in electrochemical processes $[12,13]$. Nevertheless, some nickel-catalyzed Heck vinylations have been recently reported on activated olefins $[14,15]$. Some years ago, we showed that the in situ generation of $\mathrm{Ni}(0)$ 
complexes in the presence of both the aromatic halide and the electrophile [16] represents an interesting alternative to electrochemical processes. The main advantages of the method are the use of an easily prepared $\mathrm{Ni}$ (II)bipy complex in combination with manganese dust as a reducing agent, which is not air sensitive, is compatible with fragile functions, and can be used in a catalytic amount. We showed that this nickel catalysis applies to cross-coupling reactions, efficiently leading to a variety of functionalized 2-arylpyridines [17]. More recently, this nickelcatalyzed reaction provided a convenient and mild method for a one-pot synthesis of substituted benzofurans, chromans and indoles by carbonickelation of alkynes [18]. We finally decided to extend the scope of this heterocyclization reaction to various nonactivated olefins in a nickel-catalyzed intramolecular basefree Heck-type coupling.

\section{Results and Discussion Scope of the reaction}

We applied the Nickel-catalyzed intramolecular base-free Hecktype coupling to two model substrates, assumed to provide either a benzofuran or an indole core. Our first study involved the cyclization of allyl moieties such as allyl ether $\mathbf{1 a}$ or $N$-allyl protected anilines $\mathbf{1 b}-\mathbf{c}$, easily prepared by quantitative allylation of $o$-iodophenol and o-iodoanilines using allyl bromide in DMF (Scheme 1).

Following the protocol optimized for the carbonickelation of triple bonds [19], we exposed 1a-c to a mixture containing

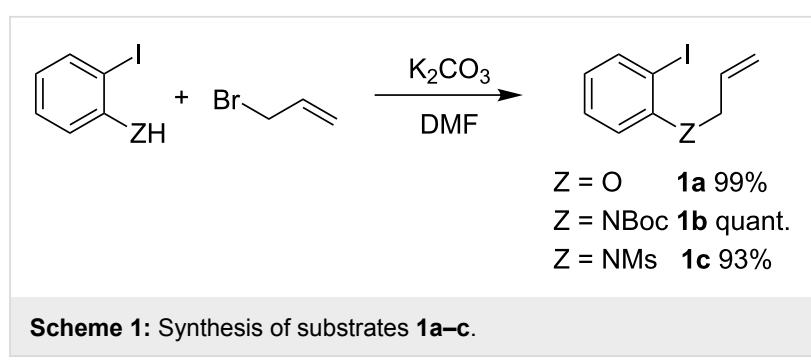

0.2 equiv of $\mathrm{NiBr}_{2}$ bipy and 2 equiv of finely grown manganese in DMF containing trace amounts of trifluoroacetic acid at $50{ }^{\circ} \mathrm{C}$ (Table 1). Disappointingly, using 1a the major new product recovered was the dimer $\mathbf{4 a}$, obtained with trace amounts of several other byproducts (Table 1, entry 1). The formation of this symmetrical dimer suggests that: (i) the oxidative addition of $\mathrm{Ni}(0)$ into the carbon-iodine bond leads to $\mathbf{1 a}-\mathrm{Ni}$, which triggers a 5-exo-trig carbonickelation on the terminal olefin; (ii) the resulting 2a-Ni does not undergo the expected $\mathrm{Ni}-\mathrm{H}$ elimination but probably evolves by disproportionation [20] leading to alkyl ${ }_{2} \mathrm{Ni}$ and $\mathrm{NiBr}_{2}$ bipy $[21,22]$. The subsequent reductive elimination of alkyl ${ }_{2} \mathrm{Ni}$ would explain the formation of the dimer $4 \mathbf{a}$.

In contrast, the carbonickelation of $\mathbf{1 b}$ led to an equimolar mixture of the expected 3-methylindole $\mathbf{2 b}$ ' (3-methyleneindoline $\mathbf{2 b}$ rearranging into 3-methylindol $\mathbf{2 b}$ ', probably during workup) and 3-methylindoline $\mathbf{3 b}$ in an overall good $60 \%$ isolated yield (Table 1, entry 2). The formation of $\mathbf{3}$ is probably due to the sluggishness of the $\mathrm{NiH}$ elimination, which allows for the

Table 1: Carbonickelation of compound 1a-c.

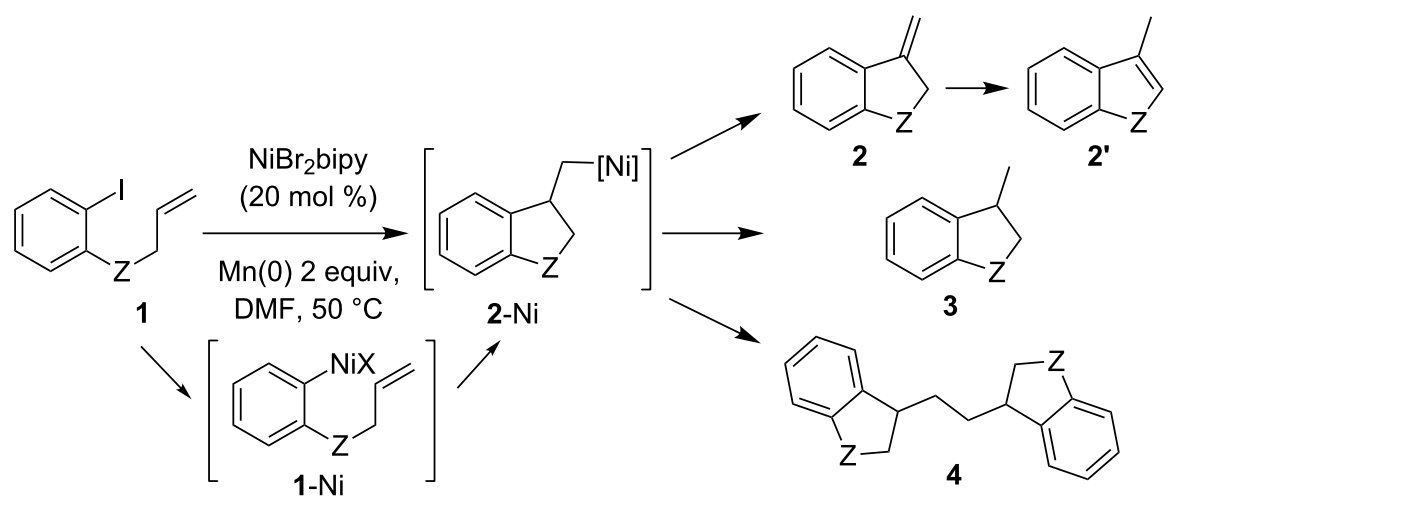

\begin{tabular}{llll}
\hline entry & Arl & Z & ratio 2/2'/3/4 \\
\hline 1 & 1a & O & $\varepsilon / \varepsilon / \varepsilon / 100\left(26 \%{ }^{\mathrm{b}}\right)$ \\
2 & 1b & N-Boc & $0 / 50 / 50 / 0(60 \%)$ \\
3 & 1c & N-Ms & $61 / 26 / 13 / 0\left(60 \%^{c}\right)$ \\
$4^{\text {d }}$ & 1c & N-Ms & $40 / 22 / 38 / 0\left(69 \%^{c}\right)$ \\
\hline
\end{tabular}

aDetermined by NMR, isolated yield between brackets; 'btrace amounts of $\mathbf{2 a}$, 2a' and 3a were identified as well as several other byproducts; 'NMR yield with respect to an internal standard, based on initial aryl iodide 1c; ${ }^{d}$ reaction run with 1 equiv of $\mathrm{NiBr}_{2}$ bipy. 
competitive protonation of the fragile intermediate alkylnickel 2-Ni. While the Pd-catalyzed reductive Heck reaction promoted by a hydride generated in situ is well known [23,24], the nickelcatalyzed process is likely to occur through a radical hydrogen transfer from the DMF [20,25]. The $N$-allylaniline 1c gives the same good yield added to an attractive $\left(\mathbf{2} \mathbf{c}+\mathbf{2} \mathbf{c}^{\mathbf{y}}\right) / \mathbf{3} \mathbf{c}$ ratio of $87 / 13$ (Table 1, entry 3 ). Formation of the 3 -methylindoline 3 is therefore disfavored when a mesyl protecting group is used instead of a carbamate. When this reaction is run with stoichiometric amounts of nickel, the reductive pathway affording indoline $\mathbf{3 c}$ is slightly increased, and a $\left(\mathbf{2} \mathbf{c}+\mathbf{2} \mathbf{c}^{\prime}\right) / \mathbf{3} \mathbf{c}$ ratio of $62 / 38$ is observed (Table 1 , entry 4 ).

In conclusion to the first part of this study, the formation and cyclization of arylnickel intermediates $\mathbf{1 - N i}$ is observed in all cases. Afterward, the stability of the exo-methylene-nickel 2-Ni seems to govern the formation of the cyclized product. Particularly, the dimerization of 2-Ni threatens the synthetic utility of this reaction, as observed in the case of $\mathbf{1 a}$. In an effort to escape this pathway, we tried to stabilize 2 -Ni by using allyl moieties that would provide secondary alkylnickel intermediates. Crotyl and cyclohexenyl ethers and amines were thus employed instead of the allyl. Compounds $\mathbf{5}$ and $\mathbf{6}$ were easily prepared by a Mitsunobu condensation involving 2-iodophenol or 2-iodo- $N$-mesylaniline and crotyl alcohol or cyclohex-2-enol (Scheme 2). An $N$-mesyl derivative was retained, with a lesser amount of indoline 3 being obtained above when this protecting group was employed.

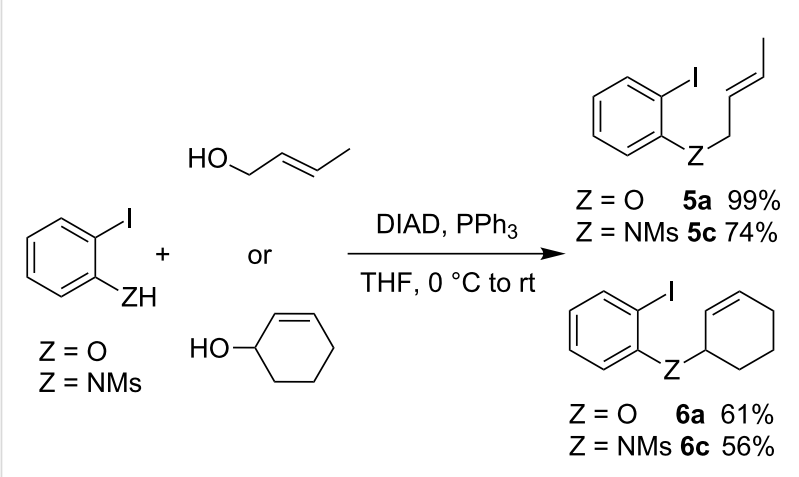

Scheme 2: Synthesis of substrates $5 a, 5 c, 6 a$ and $6 c$.

The carbonickelation protocol was applied to the cyclization of crotyl derivatives 5 (Scheme 3).

When applied to ether 5a, as expected, the substitution of the allyl moiety at the terminal position by a methyl tends to disfavor the dimerization of the alkylnickel intermediate, and type-4 dimers are no longer observed. However, the expected cyclized compound $\mathbf{7 a}$ is obtained only in trace amounts, with

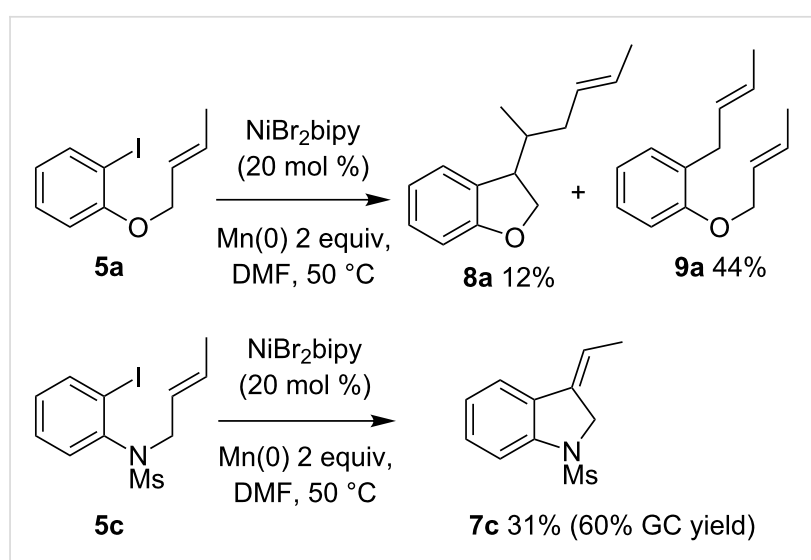

Scheme 3: Cyclization of substrate $\mathbf{5 a}$ and $\mathbf{5 c}$.

the major products isolated being compounds $\mathbf{8 a}$ and 9a. Formation of these unexpected products could result from the consecutive intermolecular reactions between $\mathbf{5 a}$ and the alkylnickel $\mathbf{7 a - N i}$ or the arylnickel $\mathbf{5 a}-\mathrm{Ni}$, respectively (Scheme 4). This reactivity is not unexpected: allyl ethers are known to be good allylating agents in the presence of nickel-bipyridine complexes [26,27]. In addition, the electroreductive allylation of aromatic or heteroaromatic halide and allylic acetate $[28,29]$ was successfully carried out using nickel-bipyridine complexes as catalysts in DMF. More recently, Weix noted that the same reaction could be achieved under chemical conditions, always using bi-(or ter-)pyridine nickel catalysts [30]. These data explain the formation of $\mathbf{9 a}$. Finally, the 8a/9a ratio suggests that 5a-Ni can undergo two competitive pathways: the 5-exotrig cyclization leading to $\mathbf{7 a - N i}$, and the aromatic allylation affording 9a. Based on the figures we conclude that $\mathbf{5 a}-\mathrm{Ni}$ reacts more rapidly with the allyl derivative than it cyclizes.

Under the same conditions, $N$-mesylaniline $\mathbf{5 c}$ is more efficient (Scheme 3), and the expected cyclized product $\mathbf{7 c}$ is obtained as the major product $(60 \%$ GC yield, $31 \%$ isolated yield due to the instability of the exocyclic double bond during the purification) [31].

In the cyclohexenyl series, we were pleased to observe that ether $\mathbf{6 a}$ affords only the benzofuran $\mathbf{1 0 a}$, but the conversion is limited (30\% of the starting material $\mathbf{6 a}$ is recovered) and the yield modest (36\% isolated, $51 \%$ based on recovered material, Scheme 5).

Interestingly, the intracyclic character of the double bond in $\mathbf{6}$ appears to influence the relative kinetics of the competing reactions in favor of both the carbonickelation and the $\beta$-elimination (thus the Heck-type coupling) over the formation of a $\pi$-allyl complex that would afford allylation products such as $\mathbf{8}$ or 9. In the aniline series, the indole $10 \mathrm{c}$ ( $50 \%$ GC yield, $28 \%$ 


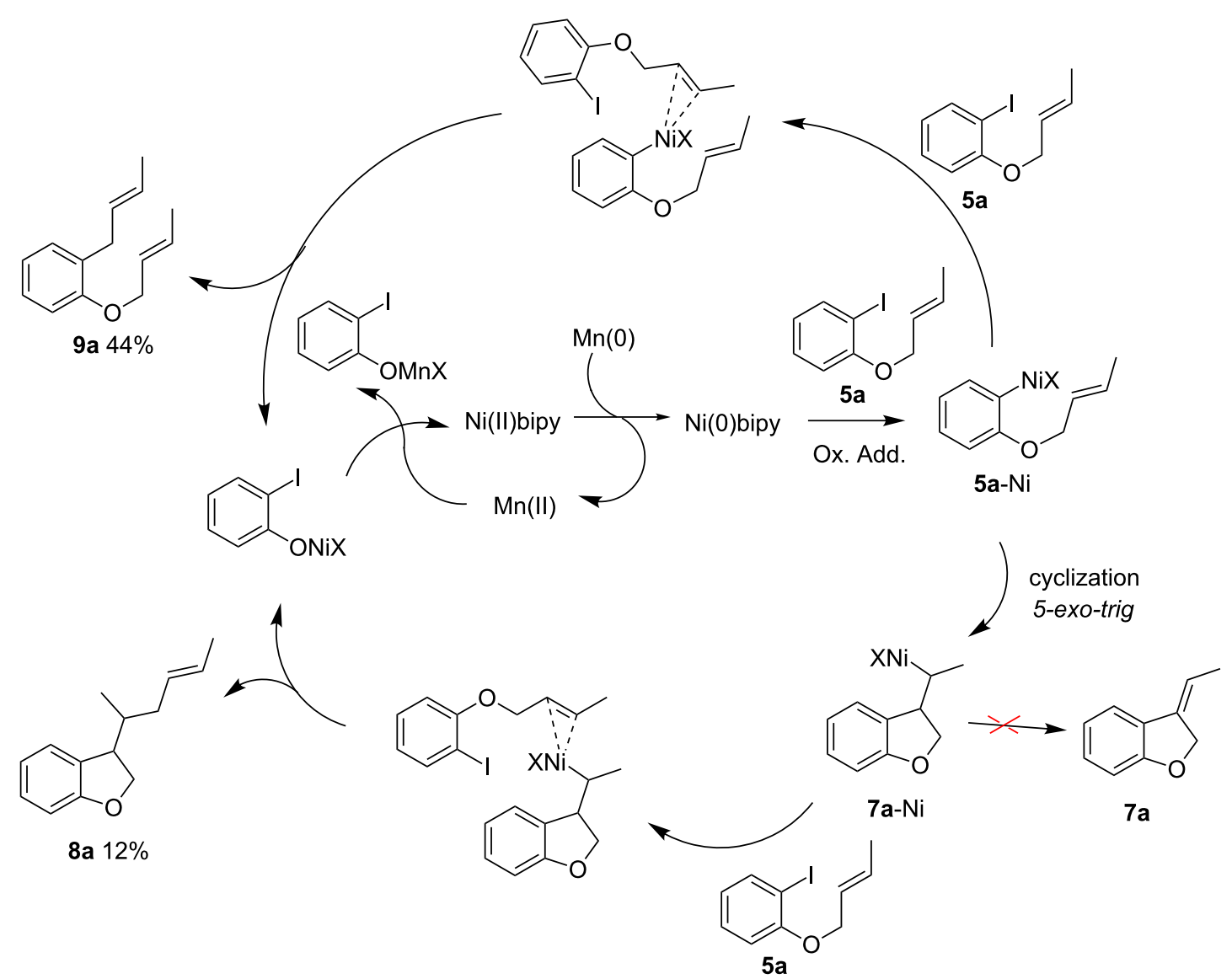

Scheme 4: Proposed mechanism involving m-allylnickel formation.

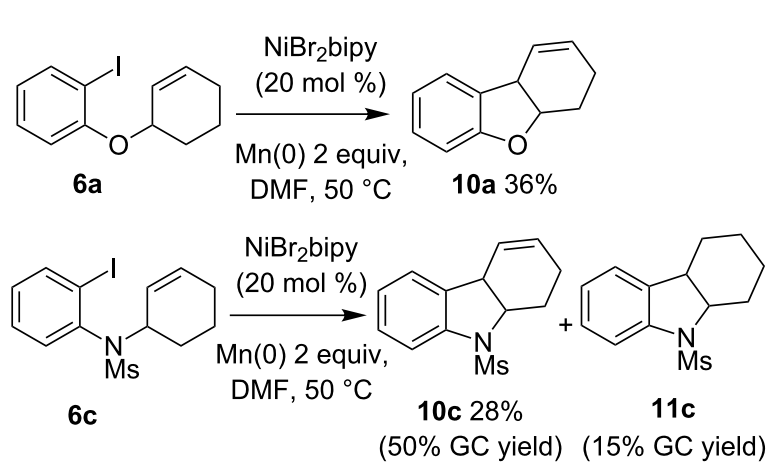

Scheme 5: Cyclization of substrate $6 \mathbf{a}$ and $6 c$.

isolated yield) is obtained together with the indoline $11 \mathbf{c}$, in an indol/indoline $10 \mathrm{c} / 11 \mathrm{c}$ ratio of $80 / 20$.

\section{Creation of an all-carbon quaternary center at a ring junction}

The success of the above experiments prompted us to conduct this reaction with trisubstituted olefins, in an effort to construct tricyclic skeletons with an all-carbon quaternary center at a ring junction. This pattern is found in important natural products such as morphine whose ACE ring system exhibits a tetrahydrodibenzofuran motif with an angular ethylamino chain on C13. We thought that the nickel-catalyzed intramolecular carbometalation reaction could help to tackle the problem of the central ring (E) closure. To validate this hypothesis, we retained substrate $\mathbf{1 3}$ as a simplified working model. If ether $\mathbf{1 3}$ is little functionalized, it bears the methylvinyl moiety that is essential to the construction of the quaternary ring junction. Substrate $\mathbf{1 3}$ was prepared by a simple Mitsunobu condensation between 2-methylcyclohex-2-enol (12), a known compound prepared in three steps from commercially available 2-methylcyclohexanone and 2-iodophenol (Scheme 6). The carbonickelation protocol applied to $\mathbf{1 3}$ led in one hour to the expected (and sole) tricyclic product $\mathbf{1 4}$ in $52 \%$ isolated yield, resulting from a nickel-catalyzed intramolecular base-free Heck-type coupling and exhibiting an all-carbon quaternary center at a cis-ring junction (as established by NOESY experiments). This result, added to that obtained above with aryl ether $\mathbf{6 a}$, underlines that the endocyclic character of the unsaturation is essential to favor the Heck coupling. The carbonickelation process leads to a secondary alkylnickel intermediate, which is sufficiently stabilized to 


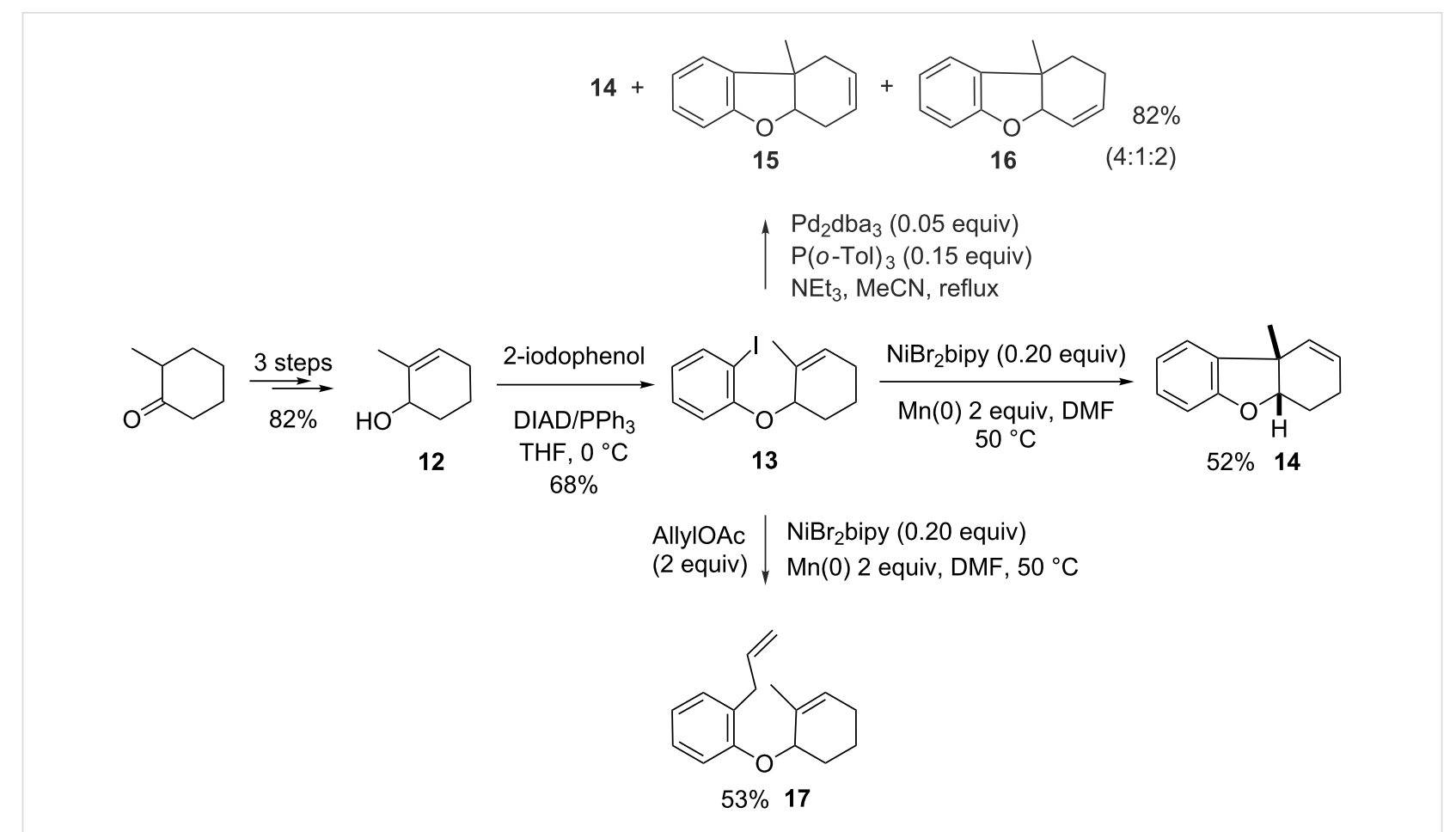

Scheme 6: Synthesis and carbometalations of 13.

avoid the side reactions observed above. Actually, the carbonickelation remains the rate-determining step as suggested by an experiment in which allyl acetate was mixed with $\mathbf{1 3}$ before the addition of the catalyst (Barbier conditions). In this case, the only product was the allylated aryl derivative $\mathbf{1 7}$, recovered in comparable yields, suggesting that in the presence of a good allyl donor, the $\sigma$-arylnickel undergoes an intermolecular allylation quicker than the intramolecular carbonickelation.

From a synthetic point of view, it is interesting to note that $\mathbf{1 4}$ was obtained as only one isomer, the double bond remaining at the location imposed by the nickel hydride elimination. In order to compare the $\mathrm{Ni}$-catalyzed version to the $\mathrm{Pd}(0)$ one, the same reaction was run following the protocol recently described by Fukuyama [32] in the key-step of his total synthesis of morphine. Under these conditions, the cyclization took place in an excellent $82 \%$ yield after $3.5 \mathrm{~h}$, but a mixture of the three regioisomers 14-16 was recovered (Scheme 6). By contrast, under Larock's conditions [33] $\left[\mathrm{Pd}(\mathrm{OAc})_{2}(5 \mathrm{~mol} \%), \mathrm{Na}_{2} \mathrm{CO}_{3}\right.$, DMF, $80{ }^{\circ} \mathrm{C}$ ], an even higher yield ( $90 \%$ after 2 days) was returned but consisted of a 1:1:1 mixture of the same three products 14-16. Replacing sodium carbonate by silver carbonate avoids these post-cyclization isomerizations [34,35], but the yield (52\% after $16 \mathrm{~h}$ ) was not higher than with nickel. Thus, this study suggests that a Heck-coupling reaction relying on a carbonickelation step can be considered as a useful tool in the total synthesis.

\section{Conclusion}

In this work, we have shown that the $\mathrm{NiBr}_{2}$ bipy complex can be used to catalyze an intramolecular Heck-type reaction in the absence of any additional base. This glove-box-free procedure occurs using $20 \%$ of $\mathrm{NiBr}_{2}$ bipy and does not require the handling of air- or moisture-sensitive reagents. Thus, this single process gives access to a simplified model of the trinuclear ACE core of morphine. Beyond the appeal of the possible replacement of expensive palladium by cheap nickel, the absence of post-coupling isomerization of the double bond seems particularly worthy of note.

\section{Experimental}

\section{General procedure for the intramolecular carbonickelation of alkenes}

To a solution of aryliodide ( $0.5-1 \mathrm{mmol}, 1$ equiv) in anhydrous DMF $(5 \mathrm{~mL})$ under argon atmosphere at $50{ }^{\circ} \mathrm{C}$ is added manganese ( 2 equiv) followed by $\mathrm{NiBr}_{2}$ bipy ( 0.2 equiv) then rapidly TFA $(20 \mu \mathrm{L})$. The medium is vigorously stirred at $50{ }^{\circ} \mathrm{C}$, and disappearance of the starting material is monitored by gas chromatography. The mixture is hydrolyzed with water $(10 \mathrm{~mL})$, diluted with $\mathrm{Et}_{2} \mathrm{O}(10 \mathrm{~mL})$, and then filtered through celite. The aqueous layer is extracted with $\mathrm{Et}_{2} \mathrm{O}(2 \times 10 \mathrm{~mL})$, and then the combined organic layers are washed with water $(3 \times 10 \mathrm{~mL})$ and brine $(2 \times 10 \mathrm{~mL})$, dried over anhydrous $\mathrm{MgSO}_{4}$, and concentrated. The crude is purified by flash chromatography. 
cis-9b-methyl-3,4,4a,9b-tetrahydrodibenzo[ $[b, c]$ furan (14)

The compound $\mathbf{1 4}$ is obtained by using ether $\mathbf{1 3}$ (314 mg, $1 \mathrm{mmol}$ ), $\mathrm{NiBr}_{2}$ bipy ( $75 \mathrm{mg}, 0.2 \mathrm{mmol}$ ), and manganese powder $(110 \mathrm{mg}, 2 \mathrm{mmol})$ in anhydrous DMF $(5 \mathrm{~mL})$ following the carbonickelation procedure. The pure $14(97 \mathrm{mg}, 0.52 \mathrm{mmol}$, $52 \%$ ) is isolated from the crude by flash chromatography on silica ( $2 \%$ of $\mathrm{Et}_{2} \mathrm{O}$ in $n$-pentane) as a colorless oil. ${ }^{1} \mathrm{H}$ NMR $\left(300 \mathrm{MHz}, \mathrm{CDCl}_{3}\right) 1.41(\mathrm{~s}, 3 \mathrm{H}), 1.78-2.03(\mathrm{~m}, 2 \mathrm{H}), 2.18-2.31$ $(\mathrm{m}, 2 \mathrm{H}), 4.62(\mathrm{t}, J=3.6 \mathrm{~Hz}, 1 \mathrm{H}), 5.51-5.56(\mathrm{~m}, 1 \mathrm{H}), 5.68-5.75$ $(\mathrm{m}, 1 \mathrm{H}), 6.79(\mathrm{dd}, J=8.4,1.0 \mathrm{~Hz}, 1 \mathrm{H}), 6.87(\mathrm{td}, J=7.2$, $0.9 \mathrm{~Hz}, 1 \mathrm{H}), 7.11(\mathrm{~d}, J=7.2 \mathrm{~Hz}, 1 \mathrm{H}), 7.12(\mathrm{td}, J=6.6,1.2 \mathrm{~Hz}$, $1 \mathrm{H}) ;{ }^{13} \mathrm{C}$ NMR $\left(75 \mathrm{MHz}, \mathrm{CDCl}_{3}\right.$ ) 19.4, 23.3, 25.1, 44.4, 87.8, $110.0,120.7,122.9,125.5,128.1,132.1,135.8,158.9$; NMR 2D NOESY: correlation between $1.41(\mathrm{~s}, 3 \mathrm{H})$ and $4.62(\mathrm{t}, J=$ $3.6 \mathrm{~Hz}, 1 \mathrm{H})$; IR (neat): 3018, 2956, 1595, 1474, 1232, $1039 \mathrm{~cm}^{-1}$; MS (CI) m/z: $186\left(\mathrm{M}^{+}\right), 171$ (M - Me, base), 143, 128; HRMS (EI): calcd for $\left(\mathrm{M}^{+}\right) \mathrm{C}_{13} \mathrm{H}_{14} \mathrm{O}$ : 186.1045 ; found: 186.1049 .

\section{Supporting Information}

\section{Supporting Information File 1}

Experimental procedures and compound characterization. [http://www.beilstein-journals.org/bjoc/content/ supplementary/1860-5397-9-81-S1.pdf]

\section{Acknowledgements}

RL is grateful to the Région de Haute-Normandie and CNRS for a PhD fellowship. We also acknowledge the CRUNCh interregional program for its financial support to our research projects.

\section{References}

1. Marek, I.; Chinkov, N.; Banon-Tenne, D. Carbometallation Reactions. In Metal-Catalyzed Cross-Coupling Reactions, 2nd ed.; de Meijere, A.; Diederich, F., Eds.; Wiley-VCH Verlag GmbH \& Co. KGaA: Weinheim, Germany, 2004; pp 395-478. doi:10.1002/9783527619535.ch7

2. Hogan, A.-M. L.; O'Shea, D. F. Chem. Commun. 2008, 3839-3851. doi:10.1039/b805595e

3. Ziegler, K.; Bähr, K. Chem. Ber. 1928, 61, 253-263. doi:10.1002/cber.19280610203

4. Heck, R. F.; Nolley, J. P. J. Org. Chem. 1972, 37, 2320-2322. doi:10.1021/jo00979a024

5. Heck, R. F. Acc. Chem. Res. 1979, 12, 146-151. doi:10.1021/ar50136a006

6. Beletskaya, I. P.; Cheprakov, A. V. Chem. Rev. 2000, 100, 3009-3066. doi:10.1021/cr9903048

7. Dounay, A. B.; Overman, L. E. Chem. Rev. 2003, 103, 2945-2964. doi:10.1021/cr020039h

See for a review on palladium-catalyzed reactions involving the Mizoroki-Heck reaction.
8. Negishi, E.-i.; Copéret, C.; Ma, S.; Liou, S.-Y.; Liu, F. Chem. Rev. 1996, 96, 365-394. doi:10.1021/cr950020x

9. Ma, S.; Negishi, E.-i. J. Org. Chem. 1994, 59, 4730-4732. doi:10.1021/jo00096a011

10. Taniguchi, T.; Zaimoku, H.; Ishibashi, H. J. Org. Chem. 2009, 74, 2624-2626. doi:10.1021/jo802787j

11. Oestreich, M. The Mizoroki-Heck reaction; John Wiley \& Sons, Ltd: Chichester, U.K., 2009.

12. Rollin, Y.; Meyer, G.; Troupel, M.; Fauvarque, J.-F.; Périchon, J. J. Chem. Soc., Chem. Commun. 1983, 793-794. doi:10.1039/C39830000793

13. Olivero, S.; Rolland, J.-P.; Duñach, E. Organometallics 1998, 17, 3747-3753. doi:10.1021/om980247t

14. Ma, S.; Wang, H.; Gao, K.; Zhao, F. J. Mol. Catal. A: Chem. 2006, 248, 17-20. doi:10.1016/j.molcata.2005.12.013

15. Gøgsig, T. M.; Kleimark, J.; Lill, S. O. N.; Korsager, S.; Lindhardt, A. T.; Norrby, P.-O.; Skrydstrup, T. J. Am. Chem. Soc. 2012, 134, 443-452. doi:10.1021/ja2084509

16. Durandetti, M.; Gosmini, C.; Périchon, J. Tetrahedron 2007, 63, 1146-1153. doi:10.1016/j.tet.2006.11.055

17. Gosmini, C.; Bassene-Ernst, C.; Durandetti, M. Tetrahedron 2009, 65, 6141-6146. doi:10.1016/j.tet.2009.05.044

18. Durandetti, M.; Hardou, L.; Lhermet, R.; Rouen, M.; Maddaluno, J. Chem.-Eur. J. 2011, 17, 12773-12783. doi:10.1002/chem.201100967

19. Durandetti, M.; Hardou, L.; Clément, M.; Maddaluno, J. Chem. Commun. 2009, 4753-4755. doi:10.1039/b902095k

20. Jahn, U. Radicals in Synthesis III. Heinrich, M. R.; Gansäuer, A., Eds.; Topics in Current Chemistry, Vol. 320; Spinger-Verlag: Berlin Heidelberg, Germany, 2012; pp 323-352. doi:10.1007/978-3-642-28123-5 Radical intermediates have been proposed in case of alkylnickel.

21. De França, K. W. R.; Navarro, M.; Léonel, E.; Durandetti, M.; Nédélec, J.-Y. J. Org. Chem. 2002, 67, 1838-1842. doi:10.1021/jo016280y

22. Jutand, A. Chem. Rev. 2008, 108, 2300-2347. doi:10.1021/cr068072h 23. Burns, B.; Grigg, R.; Sridharan, V.; Worakun, T. Tetrahedron Lett. 1988, 29, 4325-4328. doi:10.1016/S0040-4039(00)80488-8

24. Gao, P.; Cook, S. P. Org. Lett. 2012, 14, 3340-3343. doi:10.1021/ol3013167 See for a recent application.

25. Tsou, T. T.; Kochi, J. J. Am. Chem. Soc. 1979, 101, 6319-6332. doi:10.1021/ja00515a028

26. Olivero, S.; Duñach, E. Synlett 1994, 531-533. doi:10.1055/s-1994-22917

27. Franco, D.; Wenger, K.; Antonczak, S.; Cabrol-Bass, D.; Duñach, E.; Rocamora, M.; Gomez, M.; Muller, G. Chem.-Eur. J. 2002, 8, 664-672. doi:10.1002/1521-3765(20020201)8:3<664::AID-CHEM664>3.0.CO;2D

28. Durandetti, M.; Nédélec, J.-Y.; Périchon, J. J. Org. Chem. 1996, 61, 1748-1755. doi:10.1021/jo9518314

29. Durandetti, M.; Périchon, J. Synthesis 2004, 3079-3083. doi:10.1055/s-2004-834896

30. Anka-Lufford, L. L.; Prinsell, M. R.; Weix, D. J. J. Org. Chem. 2012, 77, 9989-10000. doi:10.1021/jo302086g

31. Attempts to minimize the plummeting of the yield upon purification using other chromatographic conditions (in particular replacing silica by various alumina) proved unsuccessful on comparable 3-methylidenetetrahydrobenzofurans. 
32. Uchida, K.; Yokoshima, S.; Kan, T.; Fukuyama, T. Org. Lett. 2006, 8, 5311-5313. doi:10.1021/ol062112m

33. Larock, R. C.; Stinn, D. E. Tetrahedron Lett. 1988, 29, 4687-4690. doi:10.1016/S0040-4039(00)80581-X

34. Parsons, P. J.; Charles, M. D.; Harvey, D. M.; Sumoreeah, L. R.; Shell, A.; Spoors, G.; Gill, A. L.; Smith, S. Tetrahedron Lett. 2001, 42, 2209-2211. doi:10.1016/S0040-4039(01)00111-3

35. Trost, B. M.; Tang, W.; Toste, F. D. J. Am. Chem. Soc. 2005, 127, 14785-14803. doi:10.1021/ja054449+

\section{License and Terms}

This is an Open Access article under the terms of the Creative Commons Attribution License

(http://creativecommons.org/licenses/by/2.0), which permits unrestricted use, distribution, and reproduction in any medium, provided the original work is properly cited.

The license is subject to the Beilstein Journal of Organic Chemistry terms and conditions:

(http://www.beilstein-journals.org/bjoc)

The definitive version of this article is the electronic one which can be found at: doi:10.3762/bjoc. 9.81 